\title{
CCR3-shRNA promotes apoptosis and inhibits chemotaxis and degranulation of mouse mast cells
}

\author{
HAISEN PENG ${ }^{*}$, BING LIAO* ${ }^{*}$ XINHUA ZHU, YUEHUI LIU, YINLI JIANG and SHUHONG WU \\ Department of Otolaryngology Head and Neck Surgery, The Second Affiliated Hospital of Nanchang University, \\ Nanchang, Jiangxi 330006, P.R. China
}

Received April 12, 2019; Accepted March 17, 2020

DOI: $10.3892 /$ etm.2020.8737

\begin{abstract}
Mast cells (MCs) are the major effector cells of allergic rhinitis (AR). The present study aimed to investigate the effects of $\mathrm{C}-\mathrm{C}$ chemokine receptor type 3 (CCR3) on the proliferation, apoptosis, chemotaxis and activated degranulation of mouse MCs. Mouse bone marrow-derived MCs were cultured in vitro, purified and identified using toluidine blue staining and flow cytometry. Three different CCR3-short hairpin (shRNA) lentiviral vectors were constructed and transfected into MCs, and the mRNA and protein expression levels of CCR3 were assessed by reverse transcription-quantitative PCR and western blotting. Proliferation and apoptosis of the MCs were measured using Cell Counting kit-8 (CCK-8) assays and flow cytometry, respectively. MC chemotaxis was assessed by Transwell assay and quantified using flow cytometry. The activation of MC degranulation was examined using ELISAs. The results demonstrated that MCs were appropriately isolated, and identified that CCR3-shRNA2 presented the higher knockdown effect among the three shRNAs tested. Following $96 \mathrm{~h}$ of transfection, the results of CCK-8 and flow cytometry assays demonstrated that CCR3-shRNA2 inhibited MC proliferation and promoted MC apoptosis. The results from the Transwell assay indicated that CCR3-shRNA2 restrained MC chemotaxis, whereas ELISA results demonstrated that CCR3-shRNA2 suppressed MC degranulation. In conclusion, CCR3-shRNA2 effectively downregulated CCR3 mRNA and protein expression levels in mouse MCs. In addition, CCR3-shRNA2 promoted MC apoptosis and suppressed the proliferation, chemotaxis and degranulation of mouse MCs, suggesting that CCR3-shRNA2 may serve as a therapeutic tool for the treatment of allergic rhinitis.
\end{abstract}

Correspondence to: Dr Xinhua Zhu, Department of Otolaryngology Head and Neck Surgery, The Second Affiliated Hospital of Nanchang University, 1 Minde Road, Nanchang, Jiangxi 330006, P.R. China

E-mail: xinhua_zhu89@163.com

*Contributed equally

Key words: mast cells, C-C chemokine receptor type 3, apoptosis, degranulation, RNA interference

\section{Introduction}

Allergic rhinitis (AR) is a type of immunoglobulin (Ig) E-mediated type I allergic disease that affects the nasal mucosa. It is clinically characterized by itching of the nasal passages, sneezing, nasal hypersecretion and nasal mucosal swelling, and $60-70 \%$ of patients frequently present with eye itching, reddish eye and/or lacrimation (1). Extensive attention has been paid to the treatment of AR, including antihistamines, glucocorticoids, decongestants and immunotherapy (2); however, favorable therapeutic effects have not been fully achieved due to the diverse pathogenic factors and complex pathogenesis of AR. AR pathogenesis has been the subject of numerous studies (3). In particular, mast cells (MCs), which are the major effector cells of AR, have become an important research topic $(4,5)$.

The RNA interference (RNAi) technique has become a common and effective tool for the study of gene function. This technique typically involves introducing a chemically synthesized small interfering RNA (siRNA) or short hairpin RNA (shRNA) into cells in order to interfere with a target gene, and specifically downregulate its expression (6). C-C chemokine receptor type 3 (CCR3) is a single strand G-protein-coupled receptor containing seven hydrophobic transmembrane domains, which was originally suggested to be specifically expressed on the surfaces of eosinophils (EOSs) (7). Previous studies conducted by the present research team demonstrated that CCR3 downregulation by RNAi markedly alleviated nasal cavity symptoms, significantly reduced CCR 3 mRNA expression in the peripheral blood, bone marrow and nasal lavage fluid, and notably decreased EOS infiltration in a mouse model of AR. In addition, degranulated proteins in the EOSs of peripheral blood, bone marrow and nasal lavage fluid were significantly decreased in the AR model mice by CCR3 RNAi, and in vitro experiments revealed that CCR3 downregulation in EOSs promoted apoptosis and inhibited proliferation $(8,9)$. However, other studies have reported that CCR3 is also expressed on the surfaces of Th2 cells (10), MCs (11-13) and basophils (14). Ochi et al (13) demonstrated that human $\mathrm{MC}$ progenitors express four chemokine receptors, namely CXCR2, CCR3, CXCR4 and CCR5; however, only CCR3 is maintained until MC maturation. Brightling et al (11) reported that MCs migrate to $\mathrm{CCR} 3$, and that the application of a CCR3 inhibition with a specific blocking antibody could 
significantly reduce the migration of MCs to CCR3. Similarly, Miyazaki et al (15) demonstrated that a CCR3 blockade by $\mathrm{mAb}$ or specific CCR3 antagonist was able to reduce the amount of histamine and $\beta$ hexosaminidase secreted following MC-activated degranulation.

In the present study, CCR3 lentiviral vector plasmids were constructed and transfected into mouse MCs. The efficacy of the transfection was determined by assessing CCR3 mRNA and protein expression in the MCs. Furthermore, the effects of CCR3-shRNA transfection on MC proliferation, apoptosis and chemotaxis were evaluated, in order to provide a theoretical foundation for the further investigation of AR pathogenesis.

\section{Materials and methods}

Animals. Male Balb/c mice ( $\mathrm{n}=5$; weight $20 \pm 2$ g; 4-6 weeks old) were purchased from the Laboratory Animal Science Center of Nanchang University. All animals were housed in cages with free access to food and water and were acclimated for 1 week at a controlled temperature of $24^{\circ} \mathrm{C}$ and relative humidity of $55-65 \%$, under a 12 -h light/dark cycle (lights on at 7:00 a.m.) prior to experimental surgery. All efforts were made to minimize suffering. Animal procedures were conducted according to the Guidelines for Care and Use of Laboratory Animals and were approved by the Animal Care and Use Committee of The Second Affiliated Hospital of Nanchang University.

Reagents. Mouse interleukin (IL)-3 and mouse stem cell factor (SCF) were purchased from Promega Corporation. TRIzol reagent (cat. no. CW0580S), Ultrapure RNA extraction kit (cat. no. CW0581M), HiFiScript cDNA synthesis kit (cat. no. CW2569M) and UltraSYBR Mixture (cat. no. CW0957M) were all purchased from Beijing CoWin Biotech Co., Ltd. Annexin V-fluorescein isothiocyanate (FITC)/propidium iodide (PI) Apoptosis kit (cat. no. AP101-100-kit) was purchased from Hanzhou Multi Sciences (Lianke) Biotech Co., Ltd. RIPA Lysis Buffer (cat. no. C1053) was purchased from Applygen Technologies, Inc. SuperSignal ${ }^{\circledR}$ West Pico chemiluminescent substrate (cat. no. RJ239676) was obtained from Thermo Fisher Scientific, Inc. Polyvinylidene difluoride (PVDF) membranes (cat. no. IPVH0001) were purchased from Merck KGaA. Mouse monoclonal primary antibody against GAPDH $(1: 2,000$; cat. no. TA-08) and horseradish peroxidase (HRP)-conjugated goat anti-mouse and anti-rabbit IgG secondary antibodies (1:2,000, cat. nos. ZB-2305 and cat. no. ZB-2301, respectively) were purchased from Beijing Zhongshan Jinqiao Biotechnology Co., Ltd. Rabbit monoclonal primary antibody against CCR3 (1:500; cat. no. ab32512) was purchased from Abcam. PE-CD117 (cat. no. 555714) and FITC-FCeRI $\alpha$ (cat. no. 553376) were purchased from Becton Dickinson. Mouse histamine ELISA kit (cat. no. CEA927Ge) was purchased from USCN Life Sciences, Inc. and mouse $\beta$-hexosaminidase ELISA kit (cat. no. SBJ-M0352) was purchased from SBJBio.

Culture of mouse bone marrow-derived MCs. BALB/c mice were sacrificed by cervical dislocation. Femurs and tibias were isolated, immersed in $75 \%$ ethanol for $5 \mathrm{~min}$ and rinsed with PBS. The ends of the femurs and tibias were cut off. Bone marrow was flushed out from the bones using RPMI-1640 and was collected on a plate. A single-cell suspension of bone marrow was subsequently prepared via filtering the bone marrow with a 100-mesh sieve. Cells were collected following centrifugation at $188.9 \mathrm{x}$ g at $4^{\circ} \mathrm{C}$ for $5 \mathrm{~min}$ and were washed twice with PBS. Subsequently, cells were cultured in RPMI-1640 supplemented with 10\% FBS (Gibco; Thermo Fisher Scientific, Inc.)., $10 \mu \mathrm{g} / \mathrm{ml}$ streptomycin, $100 \mathrm{IU} / \mathrm{ml}$ penicillin, $50 \mu \mathrm{mol} / 1$ non-essential amino acids, $10 \mathrm{ng} / \mathrm{ml} \mathrm{IL-3}$ and $10 \mathrm{ng} / \mathrm{ml} \mathrm{SCF}$ and were placed at $37^{\circ} \mathrm{C}$ in a humidified incubator containing $5 \% \mathrm{CO}_{2}$.

Toluidine blue staining. The medium were changed every two days, and the mast cells were detected using Toluidine blue staining. Following 4 weeks of culture, $0.5 \mathrm{ml}$ cell suspension was collected with a Pasteur tube, added dropwise onto an autoclaved cover glass covered with polylysine and then air-dried. Cells were stained with toluidine blue for $15 \mathrm{~min}$ at room temperature, washed with water, followed by acetone differentiation, gradual ethanol $(95,85$ and $75 \%)$ dehydration, xylene hyalinization and neutral resin mounting at room temperature. Slides were imaged using a microscope (CX41; Olympus Corporation; magnification, x200).

Flow cytometry for MC identification. Cells cultured for 4 weeks were collected by horizontal centrifugation (1889 x g; $5 \mathrm{~min})$ at $4^{\circ} \mathrm{C}$, washed twice and resuspended in PBS, resuspended, and the cell concentration was adjusted to $1 \times 10^{6} / \mathrm{ml}$. Cell suspension $(100 \mu \mathrm{l})$ was put into two tubes, and incubated with $0.5 \mu \mathrm{l}$ PE-CD117 and $0.2 \mu \mathrm{l}$ FITC-FCeRI $\alpha$, the specific MCs markers (16), in the dark at $4^{\circ} \mathrm{C}$ for $30 \mathrm{~min}$. A volume of $1 \mathrm{ml}$ PBS containing $2.5 \%$ FBS was added into each tube for $30 \mathrm{sec}$, cells were washed twice in PBS and centrifuged at $188.9 \times \mathrm{g}$ for $1 \mathrm{~min}$ at $4^{\circ} \mathrm{C}$, and then the supernatant was discarded. Eventually, cells were resuspended in $0.5 \mathrm{ml}$ PBS containing $2.5 \%$ FBS. Cells were analyzed by flow cytometry (NovoCyte 2060R) with NovoExpress_1.2.5_Setup_Cn_170605.20914 software provided by ACEA Biosciences Inc.

Construction of CCR3-shRNA lentivirus vector. The CCR3 gene-specific mRNA sequence was obtained from the Genebank database (http://blast.ncbi.nlm.nih. gov/Blast.cgi). Subsequently, targeting sequences interfering with the CCR3 gene were searched for using the siRNA online design tool from Ambion; Thermo Fisher Scientific, Inc. (https://www.thermofisher.com/uk/en/ home/brands/invitrogen/ambion.html). Three CCR3 target sequences were designed by General Biosystems and screened using Blast (http://blast.ncbi.nlm.nih.gov/Blast.cgi; Table I).

Cell transfection. MC cells were seeded in a 24 -well plate at a density of $1 \times 10^{5} /$ well and grown at $37^{\circ} \mathrm{C}$ for $18-24 \mathrm{~h}$ prior to lentivirus transfection. On the second day, the medium was replaced by $2 \mathrm{ml}$ fresh medium containing $6 \mu \mathrm{g} / \mathrm{ml}$ polybrene and $10 \mu \mathrm{l}$ virus suspension, and cells were incubated at $37^{\circ} \mathrm{C}$ for $4 \mathrm{~h}$. After $4 \mathrm{~h}$ incubation at $37^{\circ} \mathrm{C}$ with the vectors, $2 \mathrm{ml}$ fresh medium was added to dilute the polybrene and the cells were further cultured for 72, 96 and $144 \mathrm{~h}$, and virus-containing medium was replaced by the fresh medium in the blank control group, vector control group and CCR3-shRNA group. 
Table I. Primer sequences of the CCR3-shRNAs.

\begin{tabular}{|c|c|c|}
\hline Primer name & Direction & Primer sequences $\left(5^{\prime}-3^{\prime}\right)$ \\
\hline \multirow[t]{2}{*}{ CCR3-shRNA1 } & Forward & $\begin{array}{l}\text { GATCCGGCAGCATTGCCTGAATTTATCTTCCTGTCAGAATAAATTCAGGCAATGC } \\
\text { TGCCTTTTTG }\end{array}$ \\
\hline & Reverse & $\begin{array}{l}\text { AATTCAAAAAGGCAGCATTGCCTGAATTTATTCTGACAGGAAGATAAATTCAGG } \\
\text { CAATGCTGCCG }\end{array}$ \\
\hline \multirow[t]{2}{*}{ CCR3-shRNA2 } & Forward & $\begin{array}{l}\text { GATCCGCAGCATTGCCTGAATTTATCCTTCCTGTCAGAGATAAATTCAGGCAATG } \\
\text { CTGCTTTTTG }\end{array}$ \\
\hline & Reverse & $\begin{array}{l}\text { AATTCAAAAAGCAGCATTGCCTGAATTTATCTCTGACAGGAAGGATAAATTCAG } \\
\text { GCAATGCTGCG }\end{array}$ \\
\hline \multirow[t]{2}{*}{ CCR3-shRNA3 } & Forward & $\begin{array}{l}\text { GATCCGCTCTTCCTCTCCTCATTATGCTTCCTGTCAGACATAATGAGGAGAGGAA } \\
\text { GAGCTTTTTG }\end{array}$ \\
\hline & Reverse & $\begin{array}{l}\text { ATTCAAAAAGCTCTTCCTCTCCTCATTATGTCTGACAGGAAGCATAATGAGGAG } \\
\text { AGGAAGAGCG }\end{array}$ \\
\hline
\end{tabular}

CCR3, C-C chemokine receptor type 3; shRNA, short hairpin RNA.

Reverse transcription-quantitative PCR (RT-qPCR). Total RNA from each group of cells was isolated using TRIzol (cat. no. CW0580S; CoWin Biosciences) according to the manufacturer's instructions. cDNA was synthesized from $1 \mu \mathrm{g}$ total RNA using an HiFiScript cDNA synthesis kit (cat. no. CW2569M; CoWin Biosciences) following the manufacturer's instructions. The thermal conditions of reverse transcription were as follows: $37^{\circ} \mathrm{C}$ for $15 \mathrm{~min}$ and $85^{\circ} \mathrm{C}$ for $5 \mathrm{sec}$. qPCR analysis was then performed to evaluate CCR3 mRNA expression using UltraSYBR mixture (cat. no. CW0957M; CoWin Biosciences). The primers were designed as follows: CCR3, forward 5'-CGCTATCCAGAGGGTGAAG-3' and reverse 5'-AGCAGTGGGTGTAGGCAAT-3' (predicted amplicon length, $328 \mathrm{bp}$ ); and GAPDH, forward 5'-AAGAAG GTGGTGAAGCAGG-3' and reverse 5'-GAAGGTGGAAGA GTGGGAGT-3' (predicted amplicon length, $111 \mathrm{bp}$ ). The qPCR cycles were performed as follows: $94^{\circ} \mathrm{C}$ for $10 \mathrm{~min}$, followed by 40 cycles of $95^{\circ} \mathrm{C}$ for $15 \mathrm{sec}, 58^{\circ} \mathrm{C}$ for $30 \mathrm{sec}$ and $72^{\circ} \mathrm{C}$ for $30 \mathrm{sec}$, and a final extension at $72^{\circ} \mathrm{C}$ for $10 \mathrm{~min}$. The relative expression level of CCR3 was normalized to endogenous control GAPDH and was expressed as $2^{-\Delta \Delta \mathrm{CT}}(17)$.

Western blotting. Cells in each group were lysed using RIPA buffer on the ice for $30 \mathrm{~min}$ and the protein concentration was estimated using a bicinchoninic acid assay kit. Proteins $(60 \mu \mathrm{g})$ were boiled at $95^{\circ} \mathrm{C}$ for $5 \mathrm{~min}$ in $500 \mu \mathrm{l}$ NuPAGE $4 \mathrm{X}$ LDS sample buffer (Invitrogen; Thermo Fisher Scientific, Inc.) containing 5\% $\beta$-mercaptoethanol. Subsequently, proteins (60 $\mu \mathrm{g}$ /lane) were separated using 10\% NuPAGE Bis-Tris precast gels (Nanjing KeyGen Biotech Co., Ltd) and transferred onto PVDF membranes. Membranes were washed with TBS supplemented with $0.1 \%$ Tween 20 (TBST), blocked with $3 \%$ bovine serum albumin (Applygen Technologies, Inc.) in TBST for $2 \mathrm{~h}$ at room temperature, and incubated at $4^{\circ} \mathrm{C}$ overnight with anti-CCR3 and anti-GAPDH primary antibodies. Following three washes of 10 min with TBST, membranes were incubated with secondary antibodies for $2 \mathrm{~h}$ at room temperature. After three washes of $5 \mathrm{~min}$ with TBST, the signal on the membrane was detected using SuperSignal ${ }^{\circledR}$ West Pico chemiluminescent substrate (cat. no. RJ239676; Thermo Fisher Scientific, Inc.) and imaged with a ChemiDoc system (Bio-Rad Laboratories, Inc.). The data were analyzed via densitometry using ImageJ software 1.8.0 (National Institutes of Health) and normalized to expression of the internal control GAPDH.

Detection of MC proliferation with Cell Counting kit-8 $(C C K-8)$ assay. Cells in each group were collected following $96 \mathrm{~h}$ transfection, washed twice with PBS, and seeded in a 96-well plate at a density of $2.5 \times 10^{5} / \mathrm{ml}$. Then, $100 \mu$ l culture medium (RPMI-1640 supplemented with 10\% FBS) was added to each well (in pentaplicate for each group) and cells were cultured at $37^{\circ} \mathrm{C}$ for $0,12,48,72$ and $96 \mathrm{~h}$. CCK8 reagent (20 $\mu \mathrm{l}$; Nanjing KeyGen Biotech Co., Ltd) was then added to each well and cells were incubated at $37^{\circ} \mathrm{C}$ for $4 \mathrm{~h}$. Absorbance at $450 \mathrm{~nm}$ was then measured using a microplate reader.

Flow cytometry for detection of MC apoptosis. Cells were collected following $96 \mathrm{~h}$ transfection, and the cell concentration was adjusted to $2.0 \times 10^{5} / \mathrm{ml}$. Cell suspension from each group was centrifuged $(698.8 \times \mathrm{g}, 3 \mathrm{~min})$ at $4^{\circ} \mathrm{C}$ and the supernatant was discarded. PBS $(300 \mu \mathrm{l})$ was then added to each tube and the mixture was gently mixed. Subsequently, $5 \mu \mathrm{l}$ Annexin V-FITC and $5 \mu \mathrm{l}$ PI were added to each tube and cells were incubated in the dark at room temperature for $10 \mathrm{~min}$. Cells were then transferred into special centrifuge tube for flow apoptosis detection, and apoptosis was eventually detected using a flow cytometer (NovoCyte 2060R) and analyzed with NovoExpress_1.2.5_Setup_Cn_170605.20914 software provided by ACEA Biosciences Inc.

Transwell assay for detection of MC chemotaxis. Cells were collected following $96 \mathrm{~h}$ transfection, centrifuged (111.8 x g; $5 \mathrm{~min}$ ) at room temperature and washed twice with PBS. Cells in each group were resuspended in medium containing $10 \% \mathrm{FBS}$ and the concentration was adjusted to $2.0 \times 10^{5} / \mathrm{ml}$. Medium containing $10 \%$ FBS $(800 \mu \mathrm{l}$ in total) and $1 \mathrm{nM}$ 

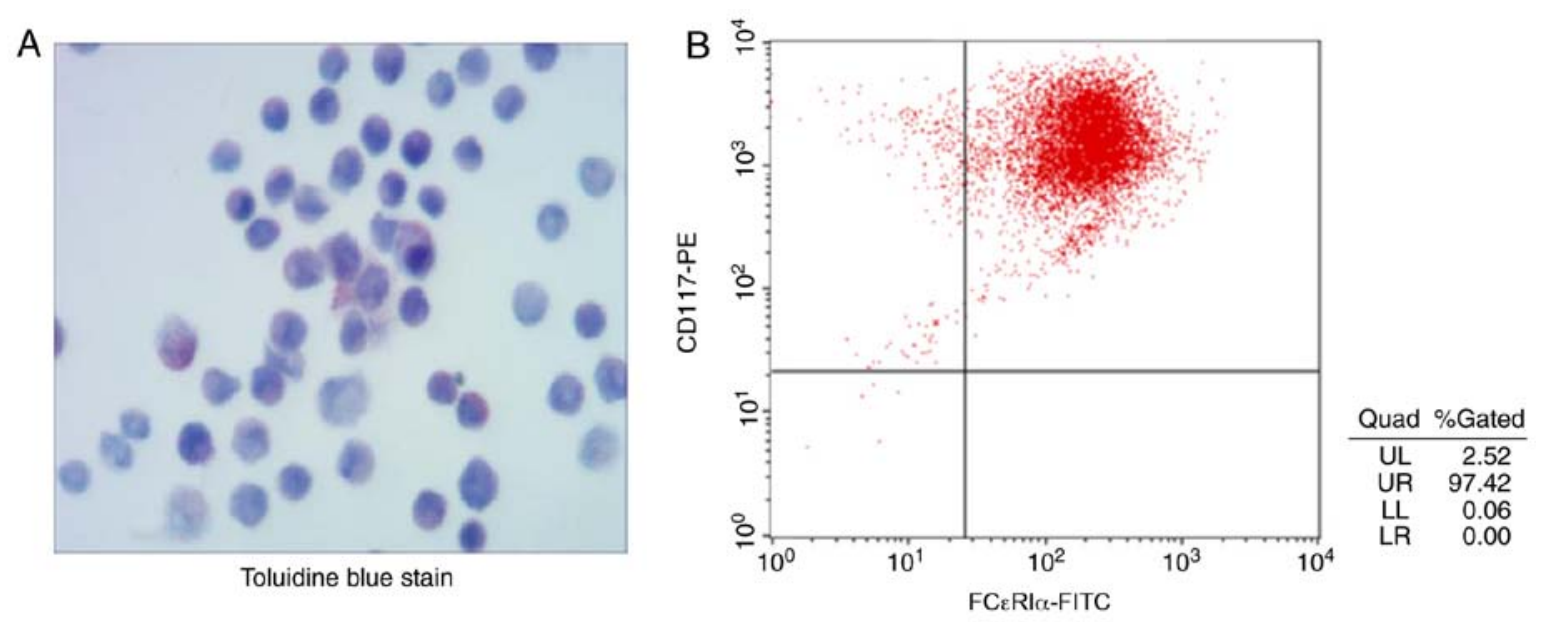

Figure 1. Identification and purification of MCs. MCs were identified following (A) toluidine blue staining (magnification, x200) and (B) flow cytometry for the cell surface antigens CD117 and FCeRI $\alpha$. The results suggested that MCs were successfully induced. MCs, mast cells

chemokines leukotriene B4 (LTB4; cat. no. 71160-24-2; Hubei Jusheng Technology Co. Ltd.) (12) were added to each well of a 24-well plate to evaluate the chemotaxis of MCs. Chambers (pore size $8 \mu \mathrm{m}$; BD Biosciences) were placed inside the wells, $200 \mu \mathrm{l}$ cell suspension from each group was added into the chambers and cells were cultured at $37^{\circ} \mathrm{C}$ for $36 \mathrm{~h}$. MCs were the suspended cells, which did not adhere to the filter membrane. Flow cytometry was subsequently used to detect the number MCs that had migrated into the lower chamber. Subsequently, the chambers were removed and the medium contained in the 24-well plate was collected and centrifuged at $1,889.4 \mathrm{x} \mathrm{g}$ at room temperature for $5 \mathrm{~min}$ before discarding the supernatant. Gr-1-FITC (5 $\mu$ l) (BD Biosciences) and C-kit PE (5 $\mu \mathrm{l})$ (BD Biosciences) were then added into each tube and the mixture was gently mixed and incubated in the dark for $10 \mathrm{~min}$ at room temperature to detect chemotaxis (18). The single-cell suspension obtained was then transferred into the special flow cytometry centrifuge tube and analyzed by using a flow cytometer (NovoCyte 2060R) and analyzed with NovoExpress_1.2.5_Setup_Cn_170605.20914 software (ACEA Biosciences Inc.). C-kit positive cells were considered to represent the number of MCs cells that had migrated.

Detection of MC degranulation by ELISA. MC degranulation was evaluated using $\beta$-hexosaminidase and Histamine detection. Cells were collected following $96 \mathrm{~h}$ transfection, centrifuged at $4^{\circ} \mathrm{C}(111.8 \times \mathrm{g} ; 5 \mathrm{~min})$ and washed twice with PBS. Cells were resuspended in medium containing 10\% FBS and the concentration was adjusted to $5.0 \times 10^{6} / \mathrm{ml}$ and seeded into 24-well plate (in sextaplicate for each group). Subsequently, $10 \mu \mathrm{g} / \mathrm{ml}$ anti-DNP IgE (19) was added into each well for $1 \mathrm{~h}$ at $37^{\circ} \mathrm{C}$ to promote the MCs activation and degranulation. Then, $40 \mathrm{ng} / \mathrm{ml}$ HSA-DNP was added for $1 \mathrm{~h}$ at $37^{\circ} \mathrm{C}$ to simulate the sensitization process and trigger allergic reactions. Subsequently, plates were placed on ice for $10 \mathrm{~min}$ in order to terminate the degranulation reaction, and centrifuged at $4{ }^{\circ} \mathrm{C}$ $(1,889.4 \mathrm{x}$ g; $5 \mathrm{~min})$ to collect the supernatants from each well. Then, $50 \mu 1$ of $1 \mathrm{mM} 4$-nitrophenyl-N-acetyl $\beta$-D-glucoside (dissolved into $100 \mathrm{mM}$ citric acid-sodium citrate, $\mathrm{pH}$ 4.4) was added to each supernatant, and the mixture was transferred

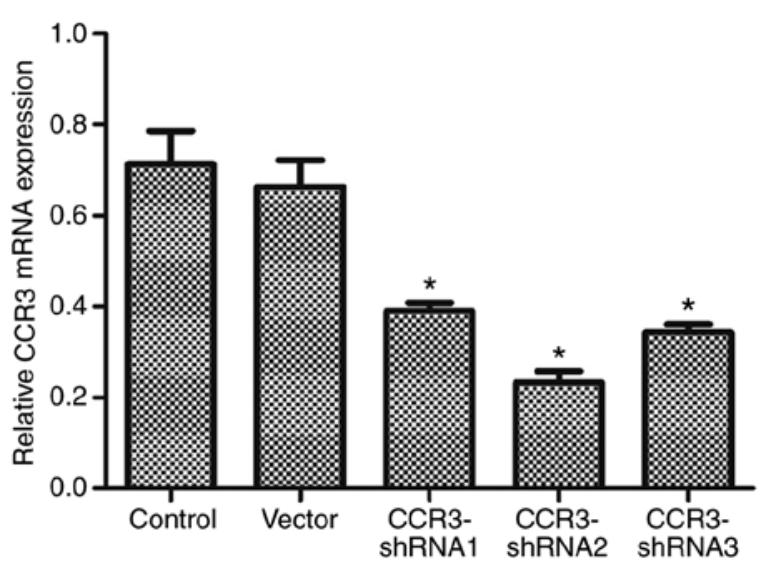

Figure 2. Reverse transcription-quantitative PCR detection of the effect of CCR3-shRNAs on CCR3 mRNA expression in mast cells. Data are expressed as the mean \pm standard deviation $(n=3)$. ${ }^{*} \mathrm{P}<0.05$ vs. control group. CCR3, C-C chemokine receptor type 3; shRNA, short hairpin RNA.

into a 96-well plate and incubated for $1 \mathrm{~h}$ at $37^{\circ} \mathrm{C}$. Sodium carbonate buffer solution $(200 \mu \mathrm{l})$ was then added to terminate the reaction. Absorbance was read at $405 \mathrm{~nm}$ using a microplate reader, and the amount of $\beta$-hexosaminidase and Histamine was expressed as its proportion of total enzymes in the unstimulated cells (20).

Statistical analysis. All data were analyzed using SPSS 19.0 software (IBM Corp.). Data are expressed as the means \pm standard deviation. Multiple group comparison was performed using one-way ANOVA followed by Tukey's post hoc test. Each experiment was repeated three times independently. $\mathrm{P}<0.05$ was considered to indicate a statistically significant difference.

\section{Results}

Identification of MCs. MCs were identified through toluidine blue staining following 4 weeks of culture of the primary MCs, since there are substances in the cytoplasm of MCs, such 

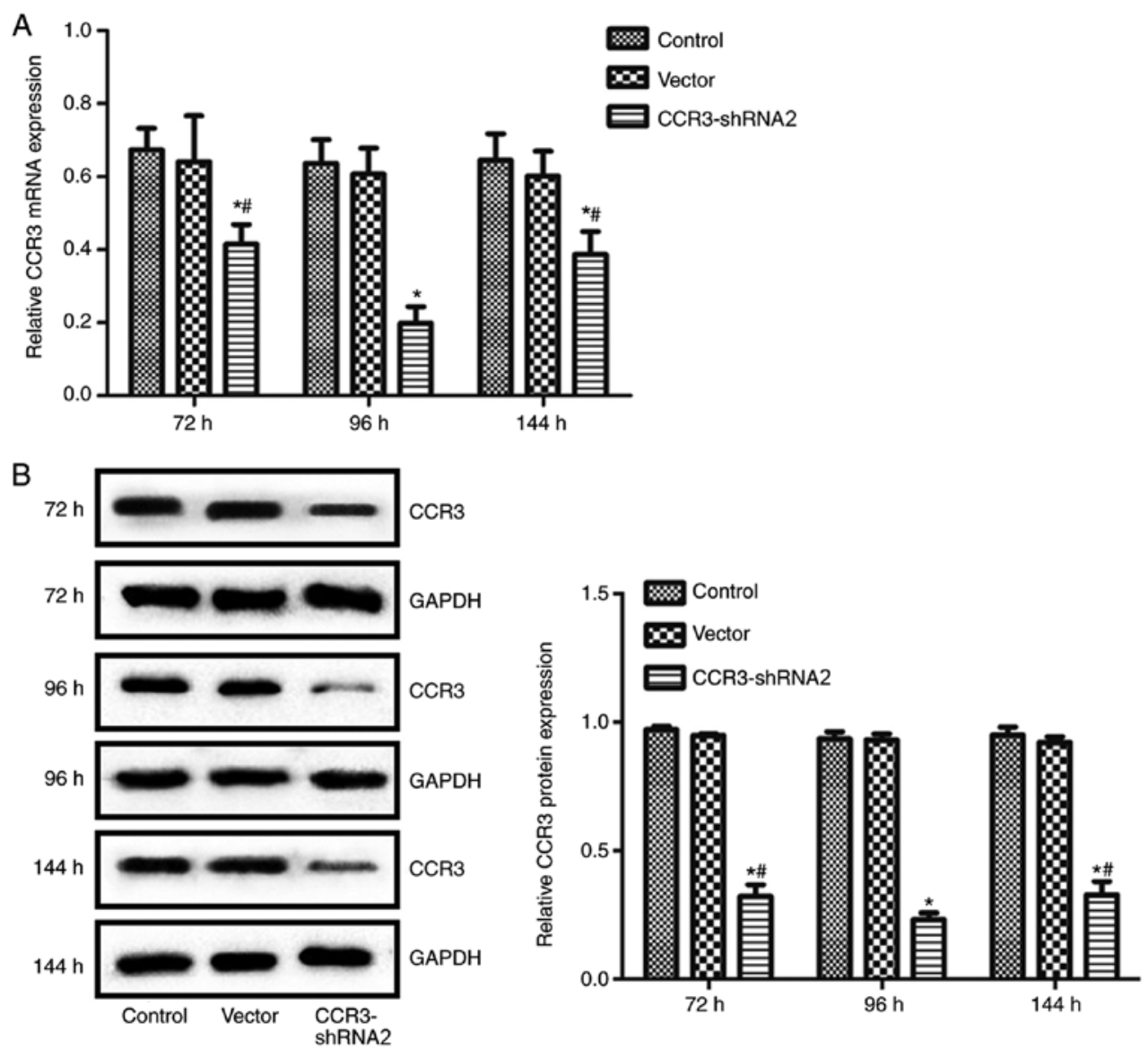

Figure 3. CCR3-shRNA2 transfection efficiency and determination of transfection time. CCR3 mRNA and protein expression were detected at 72,96 and $144 \mathrm{~h}$ following CCR3-shRNA2 transfection. (A) Detection of CCR3 mRNA expression in mast cells by reverse transcription-quantitative PCR. (B) Detection of CCR3 protein expression by western blotting and quantitative analysis. Data are expressed as the mean \pm standard deviation $(\mathrm{n}=3)$. ${ }^{*} \mathrm{P}<0.05$ vs. control group. ${ }^{\text {"P }}<0.05$ vs. CCR3-shRNA2 group at $96 \mathrm{~h}$ following transfection. CCR3, C-C chemokine receptor type 3; shRNA, short hairpin RNA.

as heparin and histamine, that create a metachromatic purple stain when they are treated with toluidine blue (21) (Fig. 1A). The results in Fig. 1B demonstrated that $97.42 \%$ of the cells were positively stained for the cell surface antigens CD117 and FCeRI $\alpha$. These results indicate that MCs were successfully induced.

Screening of CCR3-shRNA effects. As presented in Fig. 2, the three CCR3-shRNAs significantly reduced CCR3 mRNA expression compared with that in the control cells. In addition, CCR3-shRNA2 appeared to have the strongest CCR3 downregulating effect and was therefore selected for subsequent experiments. Statistical analysis was not performed statistical analysis between the three groups. The CCR3-shRNA2 downregulated CCR3 expression the most as shown in Fig. 2 and was thus selected for the following experiments.

CCR3-shRNA2 transfection efficiency and determination of the optimum transfection time. CCR 3 expression at the mRNA and protein levels were detected at 72,96 and $144 \mathrm{~h}$ post transfection with CCR3-shRNA2. The results in Fig. 3 suggest that CCR3 mRNA and protein expression levels in cells transfected with CCR3-shRNA2 were significantly reduced at each time point compared with the control group. In addition, the CCR3 expression in the CCR3-shRNA2 group at $96 \mathrm{~h}$ was significantly lower compared with that at 72 and $144 \mathrm{~h}(\mathrm{P}<0.05)$. The

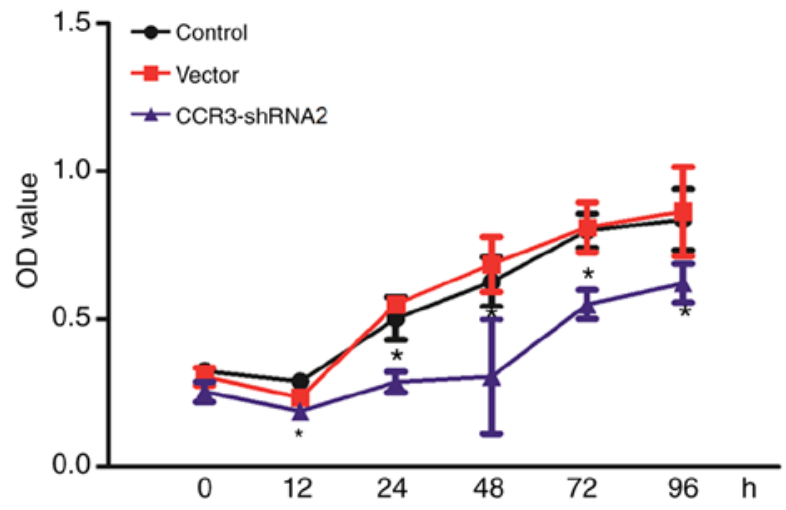

Figure 4. CCR3 interference reduces MC proliferation. Following 12-96 h of CCR3-shRNA2 transfection of MCs, cell proliferation was detected using a Cell Counting kit- 8 assay. Data are expressed as the mean \pm standard deviation $(n=3)$. ${ }^{*} \mathrm{P}<0.05$ vs. control group. CCR3, C-C chemokine receptor type 3 ; MC, mast cell; OD, optical density; shRNA, short hairpin RNA.

transfection time of $96 \mathrm{~h}$ was therefore selected for subsequent experiments.

CCR3-shRNA2 transfection decreases MC proliferation. CCK-8 assay was used to determine the effect of CCR3-shRNA2 transfection on proliferation. As presented in Fig. 4, cells in 
A

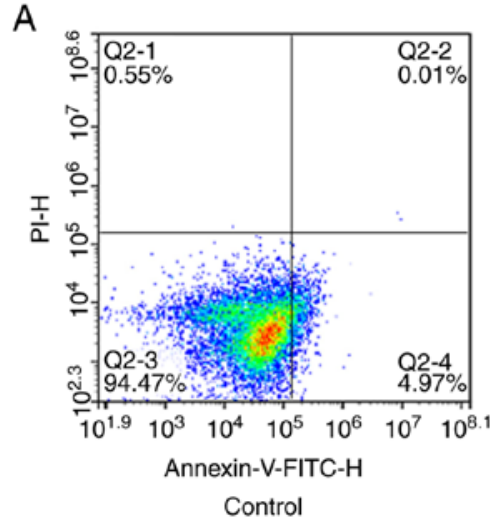

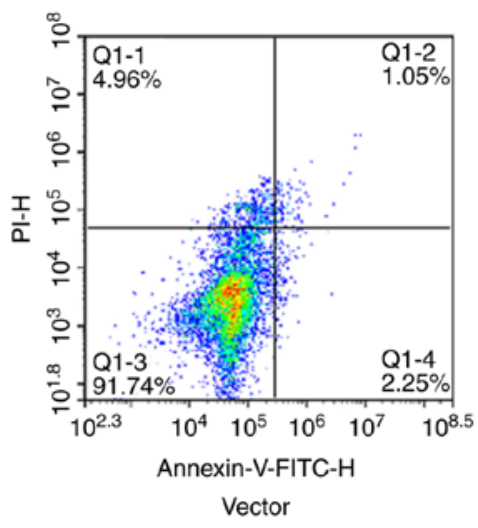

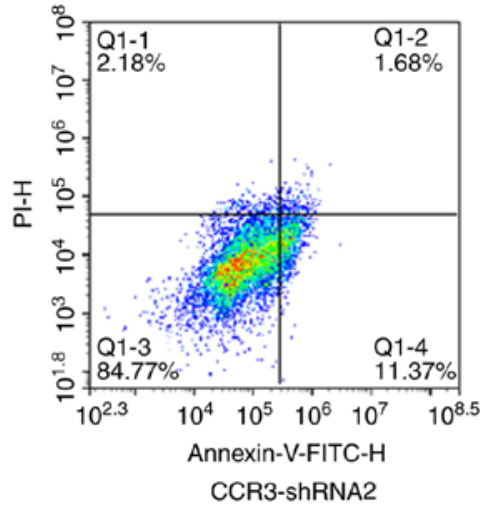

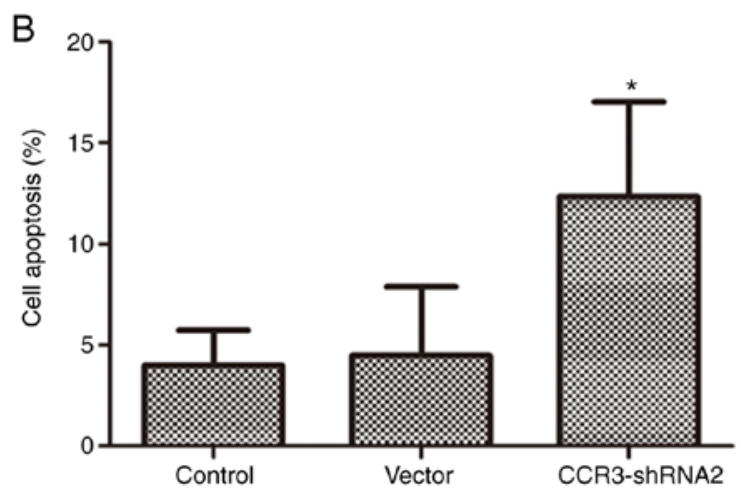

Figure 5. CCR3 interference promotes MC apoptosis. After $96 \mathrm{~h}$ of transfection, flow cytometry was performed following AnnexinV-FITC/PI staining. (A) Flow cytometry analysis of MCs transfected with CCR3-shRNA2. (B) Quantification of apoptosis in each group. Data are expressed as the mean \pm standard deviation $(\mathrm{n}=3)$. ${ }^{*} \mathrm{P}<0.05$ vs. control group. CCR3, C-C chemokine receptor type 3; FITC, fluorescein isothiocyanate; MC, mast cell; PI, propidium iodide; shRNA, short hairpin RNA.

each group proliferated in a time dependent manner. However, compared with the control group, CCR3-shRNA transfection significantly reduced the cell proliferation at each time point after $12 \mathrm{~h}(\mathrm{P}<0.05)$. These findings demonstrated that CCR3 downregulation decreased MC cell proliferation.

CCR3-shRNA2transfection promotes MCapoptosis.Following $96 \mathrm{~h}$ of cell transfection with CCR3-shRNA2, apoptosis was assessed by flow cytometry using AnnexinV-FITC/PI staining. As presented in Fig. 5, apoptosis in the CCR3-shRNA2 group was significantly increased compared with that in the control group $(\mathrm{P}<0.05)$. This result indicates that $\mathrm{CCR} 3$ downregulation promoted apoptosis in MCs.

CCR3-shRNA2 transfection decreases MC chemotaxis. The migration of MCs towards the chemokine LTB4 was detected using a Transwell assay. The results in Fig. 6 demonstrate that MC chemotaxis was significantly reduced following CCR3-shRNA2 transfection $(\mathrm{P}<0.05)$.

CCR3-shRNA2 transfection decreases the degranulation of MCs. Histamine and $\beta$-hexosaminidase are granules synthesized by MCs. They are important markers of MC degranulation (22). ELISAs were performed to detect the histamine and $\beta$-hexosaminidase release rate during $\mathrm{MC}$ degranulation. The results in Fig. 7 demonstrate that the release of histamine and $\beta$-hexosaminidase into the supernatant by CCR3-shRNA2 transfected MCs was significantly reduced compared with that of control cells $(\mathrm{P}<0.05)$.

\section{Discussion}

MCs were first isolated by Ehrlich et al from blood samples and connective tissue in 1878 (23). Since then, MCs have been considered as the major effector cells in allergic diseases, including asthma, atopic dermatitis and AR $(5,24)$. The binding of antigen-specific IgE to FCeRI to sensitize MCs has been convincingly linked to the pathophysiology of anaphylaxis and other acute allergic reactions (25). MCs originate from bone marrow-derived pluripotent hematopoietic cells and circulate as immature precursors. However, after entering tissues, they develop into functional MCs via multiple signals that prompt their proliferation and differentiation $(26,27)$. SCF and IL-3 are the most important stimulating factors for MC maturation. IL-3 is also called the polyclonal colony stimulating factor, and is the most potent cytokine able to promote early-stage mouse MC differentiation (28). SCF maintains MC survival and promotes $\mathrm{MC}$ proliferation, and its concentration will directly affect the number of MCs in the circulation and tissues, In addition, SCF can assist IL-3-mediated MC differentiation and serves a key role in late stage MC maturation (29). At present, SCF and IL-3 are frequently used to induce the differentiation of mouse bone marrow-derived MCs; however, the concentration of each factor used varies between studies. In the present study, the concentration of $10 \mathrm{ng} / \mathrm{ml}$ was used for both factors, medium was replaced every 7 days, and cells were identified 4 weeks after the induction of differentiation through toluidine blue staining and flow cytometry. The flow cytometry results demonstrated that $>97 \%$ cells were positively stained 

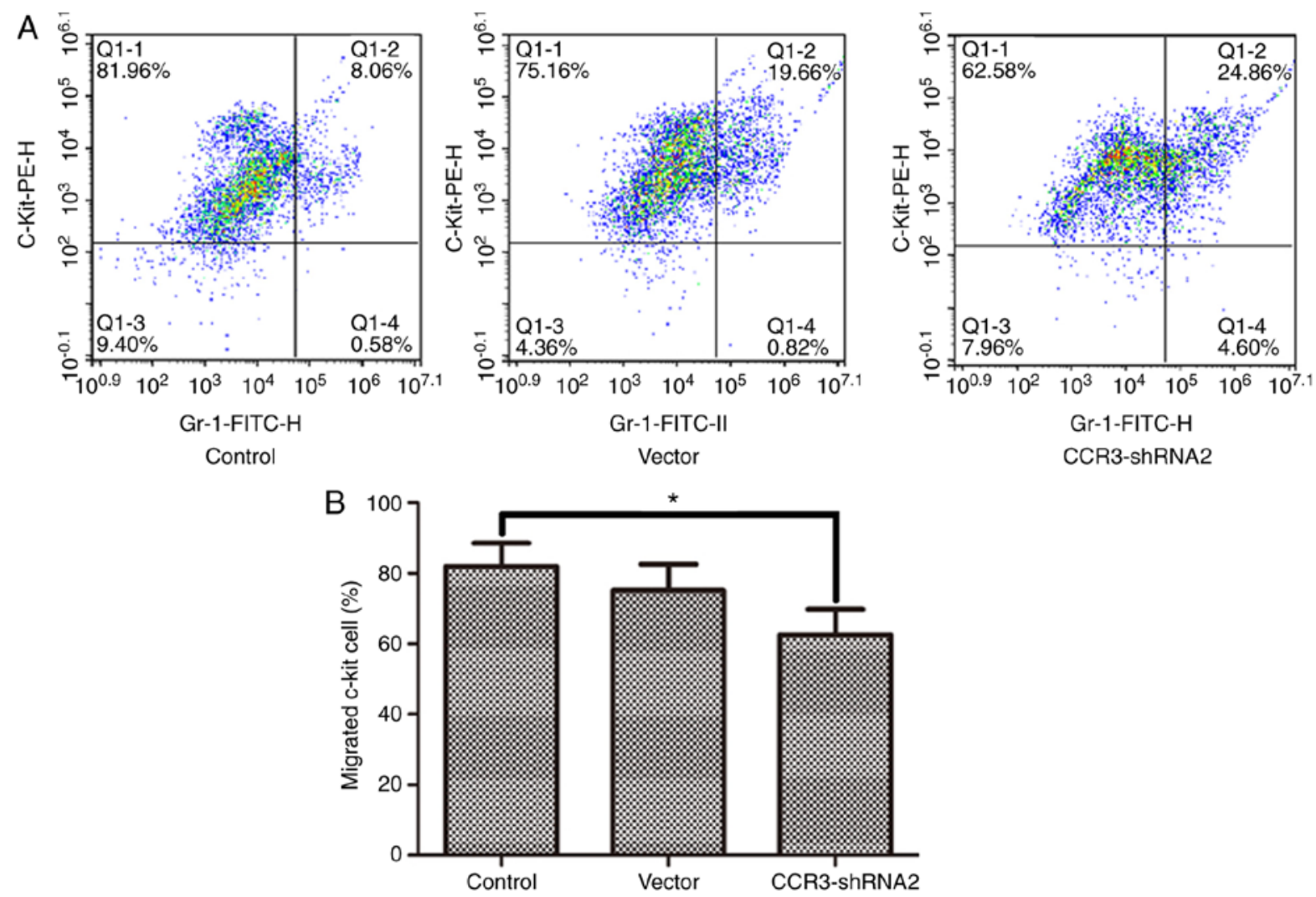

Figure 6. CCR3 interference suppresses MC chemotaxis. (A) Representative images of flow cytometry results for MC chemotaxis from each group. (B) Quantification of the percentage of migrated c-kit cells in each group. Data are expressed as the mean \pm standard deviation ( $n=3$ ). ${ }^{*} \mathrm{P}<0.05$ vs. control group. CCR3, C-C chemokine receptor type 3; FITC, fluorescein isothiocyanate; MC, mast cell; PE, phycoerythrin; shRNA, short hairpin RNA.
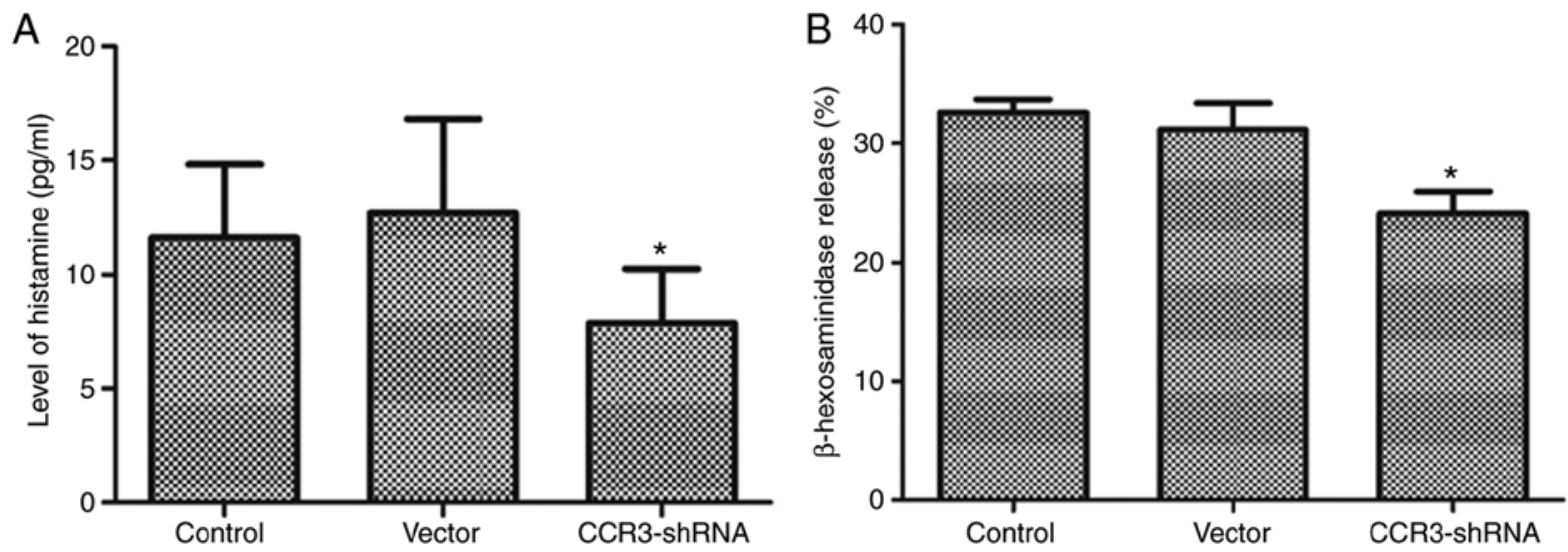

Figure 7. CCR 3 interference suppresses mast cell degranulation. (A) Histamine and (B) $\beta$-hexosaminidase levels were detected by ELISA. Data are expressed as the mean \pm standard deviation $(\mathrm{n}=3)$. ${ }^{*} \mathrm{P}<0.05$ vs. control group. CCR3, $\mathrm{C}-\mathrm{C}$ chemokine receptor type 3 ; shRNA, short hairpin RNA.

for $\mathrm{CC} 117$ and FCeRI, confirming that the purity of MCs obtained was high. With regards to the role of MCs in AR, Lin et al (30) investigated a mouse mode of AR and the results from toluidine blue staining of the nasal mucosa suggested that MC infiltration was significantly increased; furthermore, the concentrations of specific IgE and histamine in peripheral blood and IL-4, IL-9 and IL-17 in nasal lavage fluid were significantly increased compared with those in normal controls. In addition, following downregulation of potassium calcium-activated channel subfamily $\mathrm{N}$ member 4 (KCa3.1) expression using a lentivirus vector plasmid, the symptoms of AR in the AR model mice were markedly ameliorated, $\mathrm{MC}$ infiltration into the nasal mucosa was reduced, and the concentrations of specific $\operatorname{IgE}$ and histamine in peripheral blood and of IL-4, IL-9 and IL-17 in nasal lavage fluid were significantly decreased. Furthermore, in vitro experiments demonstrated that KCA3.1 downregulation in the MC cell line P815 significantly downregulated MC degranulation and IL-6 and IL-8 release (30). Shao et al (31) used the traditional Chinese medicine Shenqi in AR mice and the MC cell line $\mathrm{RBL}-2 \mathrm{H} 3$, and reported that this treatment could regulate $\mathrm{MC}$ degranulation and treat AR. Zhang et al (32) described similar 
results using the traditional Chinese medicine curcumin. These findings suggest that MC proliferation, local infiltration and degranulation serve key roles in the pathogenesis of AR. Reducing MC proliferation, infiltration and degranulation, and promoting $\mathrm{MC}$ apoptosis might therefore be crucial in the treatment of AR.

Previous studies conducted by the present research team demonstrated that CCR3 downregulation can promote eosinophil apoptosis, and suppress the proliferation and degranulation of eosinophils, which could therefore be used to treat AR $(8,9)$. However, the role of the CCR3 gene in MCs proliferation or apoptosis remains controversial $(12,33)$. Collington et al (12) compared bone marrow-derived MCs from CCR3 knockout and wild-type mice, and reported that CCR3 knockout mice shared a similar MC phenotype with wild-type mice, and that both MC types had similar migratory capacity towards the chemokines LTB4 and SCF, suggesting that the CCR3 gene has no influence on mouse MC chemotaxis. Furthermore, Brightling et al (11) demonstrated that MCs can migrate towards CCR3 chemokine, and that the use of CCR3 inhibitor can markedly decrease the migratory capacity of MCs towards this chemokine. Miyazaki et al (15) reported that the histamine and $\beta$-hexosaminidase release following MC degranulation in CCR3 gene knockout mice was significantly decreased, suggesting that the role of CCR3 gene in MC degranulation remains unclear. The present study demonstrated that MC proliferation was significantly decreased following CCR3 downregulation in mouse-derived MCs compared with the control group. In addition, the migratory capacity of CRR3-shRNA transfected MCs towards the chemokine LTB4 was also significantly reduced compared with the control group, indicating that CCR3 interference could reduce MC proliferation and chemotaxis. HSA-DNP and anti-DNP IgE were used to activate MCs proliferation, in order to assess MC degranulation. The results demonstrated that the levels of histamine and $\beta$-hexosaminidase release following MC degranulation were significantly decreased in the CCR3-shRNA transfected MC group compared with the control group, suggesting that CCR 3 interference may suppress MC degranulation. Furthermore, the results of flow cytometry and CCK-8 assays demonstrated that CCR3 interference may promote $\mathrm{MC}$ apoptosis and reduce MC proliferation.

This study exhibits some limitations. Firstly, as the study was only restricted to the in vitro detection of MC function, the results should be further verified using in vivo experiments. Secondly, the study only determined the effect of MC phenotype and CCR3 function on MC chemotaxis and degranulation, and the mechanisms involved were not evaluated. Future investigation will therefore focus on the underlying mechanisms of CCR3.

In conclusion, CCR3 interference may promote $\mathrm{MC}$ apoptosis and reduce MC proliferation, chemotaxis and degranulation, thereby alleviating the MC-mediated allergic inflammatory reaction observed in AR. To the best of our knowledge, the present study was the first to investigate the effect of CCR3 interference on MCs and to explore the roles of CCR3 and MCs in the pathogenesis of AR. The findings from this study may provide a theoretical basis for the use of CCR3 as a potential target in the treatment of AR and lay a favorable foundation for further investigation.

\section{Acknowledgements}

Not applicable.

\section{Funding}

The present study was supported by the National Natural Science Foundation of China (grant no. 81560171) and the Talent Team Project of Jiangxi Province (grant no. 20161BCB24010).

\section{Availability of data and materials}

The datasets used and/or analyzed during the present study are available from the corresponding author on reasonable request.

\section{Authors' contributions}

HP isolated the cells from mouse, cultured cells and performed cell biology experiments. BL performed plasmid construction. XZ designed this study and was a major contributor in writing the manuscript. YL performed plasmid transfection and identification. YJ analyzed the data. SW contributed to the design of the study and revised the manuscript. All authors read and approved the final version of the manuscript.

\section{Ethics approval and consent to participate}

All of the animal procedures were conducted in accordance with the Guidelines for Care and Use of Laboratory Animals, and were approved by the Animal Care and Use Committee of The Second Affiliated Hospital of Nanchang University.

\section{Patient consent for publication}

Not applicable.

\section{Competing interests}

The authors declare that they have no competing interests.

\section{References}

1. Bousquet J, Schunemann HJ, Hellings PW, Arnavielhe S, Bachert C, Bedbrook A, Bergmann KC, Bosnic-Anticevich S, Brozek J, Calderon M, et al: MACVIA clinical decision algorithm in adolescents and adults with allergic rhinitis. J Allergy Clin Immunol 138: 367-374.e2, 2016.

2. Utomo BSR, Hatta M, Sirait RH, Pratiwi S and Massi MN: The role of cytokine interleukin-2, transcription factor of FoxP3 in the immunological regulation of allergic rhinitis. Int J Otolaryngol Head Neck Surg 7: 7-19, 2017.

3. Eifan AO and Durham SR: Pathogenesis of rhinitis. Clin Exp Allergy 46: 1139-1151, 2016.

4. Im YS, Lee B, Kim EY, Min JH, Song DU, Lim JM, Eom JW, Cho HJ, Sohn Y and Jung HS: Antiallergic effect of gami-hyunggyeyeongyotang on ovalbumin-induced allergic rhinitis in mouse and human mast cells. J Chin Med Assoc 79: 185-194, 2016.

5. Modena BD, Dazy K and White AA: Emerging concepts: Mast cell involvement in allergic diseases. Transl Res 174: 98-121, 2016.

6. Ma J, Song Y, Wu B, Jiang M, Li K, Zhu C and Wen F: Production of transgenic rice new germplasm with strong resistance against two isolations of Rice stripe virus by RNA interference. Transgenic Res 20: 1367-1377, 2011.

7. Liu Y,Zhu X and Zhang H: Effects of chemokine receptor 3 gene silencing by RNA interference on eosinophils. Exp Ther Med 13: 215-221, 2017. 
8. Zhu XH, Liao B, Liu K and Liu YH: Effect of RNA interference therapy on the mice eosinophils CCR3 gene and granule protein in the murine model of allergic rhinitis. Asian Pac J Trop Med 7: 226-230, 2014

9. Zhu XH, Liao B, Xu Y, Liu K, Huang Y, Huang QL and Liu YH: Downregulation of mouse CCR3 by lentiviral shRNA inhibits proliferation and induces apoptosis of mouse eosinophils. Mol Med Rep 15: 696-702, 2017.

10. Andalib A, Doulabi H, Maracy MR, Rezaei A and Hasheminia SJ: CCR3, CCR4, CCR5, and CXCR3 expression in peripheral blood CD4+ lymphocytes in gastric cancer patients. Adv Biomed Res 2: 31, 2013.

11. Brightling CE, Kaur D, Berger P, Morgan AJ, Wardlaw AJ and Bradding P: Differential expression of CCR 3 and CXCR3 by human lung and bone marrow-derived mast cells: Implications for tissue mast cell migration. J Leukoc Biol 77: 759-766, 2005.

12. Collington SJ, Westwick J, Williams TJ and Weller CL: The function of CCR3 on mouse bone marrow-derived mast cells in vitro. Immunology 129: 115-124, 2010

13. Ochi H, Hirani WM, Yuan Q, Friend DS, Austen KF and Boyce JA: T helper cell type 2 cytokine-mediated comitogenic responses and CCR3 expression during differentiation of human mast cells in vitro. J Exp Med 190: 267-280, 1999.

14. Khanolkar A, Burden SJ, Hansen B, Wilson AR, Philipps GJ and Hill HR: Evaluation of CCR3 as a basophil activation marker. Am J Clin Pathol 140: 293-300, 2013.

15. Miyazaki D, Nakamura T, Ohbayashi M, Kuo CH, Komatsu N, Yakura K, Tominaga T, Inoue Y, Higashi H, Murata M, et al: Ablation of type I hypersensitivity in experimental allergic conjunctivitis by eotaxin-1/CCR3 blockade. Int Immunol 21 : 187-201, 2009.

16. Zhang WN, Wu K, Zhou HM, Peng QZ, He WT, Gao Y, Lin XG, Fang ZM and Chen ZH: Cultivation and identification of bone marrow mast cells in mouse. J Intern Intensive Med 15: 42-44, 2009

17. Livak KJ and Schmittgen TD: Analysis of relative gene expression data using real-time quantitative PCR and the 2(-Delta Delta C(T)) method. Methods 25: 402-408, 2001

18. Vink E, Willemien V, Michiel V, Wilko S, Evert-Jan V, Blankestijn P, Yao Y, Harrison J, Davis G and Sammut I: Novel invasive strategies in antihypertensive treatment-Renal sympathetic denervation, baroreflex stimulation. Nephrol Dial Transplant 27 (Suppl 2): ii38, 2012.

19. Varga JM, Kalchschmid G, Klein GF and Fritsch P: Mechanism of allergic cross-reactions-I. Multispecific binding of ligands to a mouse monoclonal anti-DNP IgE antibody. Mol Immunol 28: 641-654, 1991

20. Bojarová P, Bruthans J and Křen V: $\beta$-N-Acetylhexosaminidases-the wizards of glycosylation. Appl Microbiol Biotechnol 103: 7869-7881, 2019.

21. Dahal BK, Kosanovic D, Messinger J, Fischer Y, Hoffmann K, Antel J, Husen B, Hanke N, Mayet S and Ghofrani HA: Role of mast cells and chymase in pulmonary vascular remodeling. Eur Respir J 38: 1524, 2011.
22. Zudaire E, Martínez A, Garayoa M, Pío R, Kaur G, Woolhiser MR, Metcalfe DD, Hook WA, Siraganian RP and Guise TA: Adrenomedullin is a cross-talk molecule that regulates tumor and mast cell function during human carcinogenesis. Am J Pathol 168: 280-291, 2006.

23. Fisher ER: Tissue mast cells. J Am Med Assoc 173: 171-173, 1960.

24. Krystel-Whittemore M, Dileepan KN and Wood JG: Mast cell: A multi-functional master cell. Front Immunol 6: 1-12, 2016.

25. Galli SJ and Tsai M: IgE and mast cells in allergic disease. Nat Med 18: 693, 2012.

26. Ribatti D: The development of human mast cells. An historical reappraisal. Exp Cell Res 342: 210-215, 2016.

27. Schmetzer O, Valentin P, Church MK, Maurer M and Siebenhaar F: Murine and human mast cell progenitors. Eur J Pharmacol 778: 2-10, 2016.

28. Desai A, Jung MY, Olivera A, Gilfillan AM, Prussin C, Kirshenbaum AS, Beaven MA and Metcalfe DD: IL-6 promotes an increase in human mast cell numbers and reactivity through suppression of suppressor of cytokine signaling 3. J Allergy Clin Immunol 137: 1863-1871.e6, 2016.

29. Bérard F, Ferrier Le Bouëdec MC, Bouillet L, Reguiai Z, Barbaud A, Cambazard F, Milpied B, Pelvet B, Kasujee I and Gharbi H: Omalizumab in patients with chronic spontaneous urticaria nonresponsive to $\mathrm{H} 1$-antihistamine treatment: Results of the phase IV open-label SUNRISE study. Br J Dermatol 180: 56-66, 2019.

30. Lin H, Zheng CQ, Li J, Yang C and Hu L: Lentiviral shRNA against $\mathrm{KCa} 3.1$ inhibits allergic response in allergic rhinitis and suppresses mast cell activity via PI3K/AKT signaling pathway. Sci Rep 5: 13127, 2015.

31. Shao YY, Zhou YM, Hu M, Li JZ, Chen CJ, Wang YJ, Shi XY, Wang WJ and Zhang TT: The Anti-allergic rhinitis effect of traditional Chinese medicine of shenqi by regulating mast cell degranulation and Th1/Th2 cytokine balance. Molecules 22: pii: E504, 2017.

32. Zhang N, Li H, Jia JH and He MQ: Anti-inflammatory effect of curcumin on mast cell-mediated allergic responses in ovalbumin-induced allergic rhinitis mouse. Cell Immunol 298: 88-95, 2015.

33. Gangwar RS, Landolina N, Arpinati L and Levi-Schaffer F: Mast cell and eosinophil surface receptors as targets for anti-allergic therapy. Pharmacol Ther 170: 37-63, 2017. International (CC BY-NC-ND 4.0) License. 